\title{
Effect of drug-induced pathomorphosis on oral cavity organs and tissues in chronic obstructive pulmonary disease combined with coronary heart disease: A clinical case
}

\author{
Nataliya Emelyanova*([) , Irina Komir ${ }^{\circledR}$
}

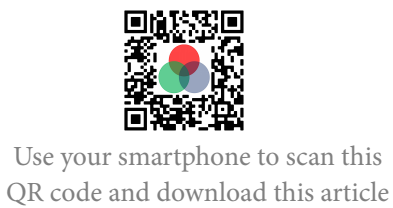

Department of Complex Risk Reduction of Chronic Non-Communicable Diseases, Government Institution "L.T. Malaya Therapy National Institute of the National Academy of Medical Sciences of Ukraine", 61000, 2a Lyubov Malaya Ave., Kharkov, Ukraine

\section{Correspondence}

Nataliya Emelyanova, Department of Complex Risk Reduction of Chronic Non-Communicable Diseases, Government Institution "L.T. Malaya Therapy National Institute of the National Academy of Medical Sciences of Ukraine", 61000, 2a Lyubov Malaya Ave., Kharkov, Ukraine

Email: natadenta@gmail.com

History

- Received: Dec 04, 2020

- Accepted: Jan 12, 2021

- Published: Jan 29, 2021

DOI : 10.15419/bmrat.v8i1.657

\section{Check for updates}

\section{Copyright}

(-) Biomedpress. This is an openaccess article distributed under the terms of the Creative Commons Attribution 4.0 International license.

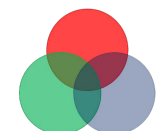

BioMedPress

The Open Access Publisher

\begin{abstract}
This article describes the clinical case of a patient, as well as the associated literature data, confirming the direct mutual influence of lesions in the oral cavity and bronchocardiac complex pathology. Special attention has been paid to the side effects of the main drugs prescribed in the basic therapy of chronic obstructive pulmonary disease combined with coronary heart disease. It is noted that drug-induced pathomorphosis can cause the development of periodontal lesions. Insufficient knowledge of these issues and the practical need for corrective measures to be taken by dentists with this category of patients indicates the relevance of research in this direction.
\end{abstract}

Key words: chronic obstructive pulmonary disease, coronary heart disease, gum epithelium, periodontal

\section{INTRODUCTION}

The diagnosis and treatment of pathological changes in the oral cavity related to somatic diseases is an important aspect of the successful work of dentists around the world. Most diseases of the internal organs provoke changes in the oral cavity, exerting both direct and indirect effects on the pathways involved in the lesion's pathogenesis. It was found that periodontal disease can accompany somatic pathology in $20-25 \%$ of cases. Type 2 diabetic individuals with severe periodontal disease were identified to have 3.2 times the risk of mortality due to ischemic heart disease compared to individuals with no or mild periodontal disease ${ }^{1,2}$.

One of the most common somatic diseases that causes various dental lesions is chronic obstructive pulmonary disease (COPD). This is associated with a high prevalence and anatomical/functional unity with the oral cavity organs. According to the data of Shen et al., it has been shown that patients with COPD are at a higher risk of developing periodontal diseases than the general population. In addition, patients who receive corticosteroid treatment are at a higher risk of developing periodontal diseases ${ }^{3,4}$. Large-scale epidemiological studies have shown there to be a close interconnection between COPD and coronary heart disease (CHD). This is associated with the common links in pathogenesis ${ }^{5}$.

In patients who suffer from COPD combined with $\mathrm{CHD}$, in addition to systemic inflammation, there are changes in the linear and volumetric blood flows as well as the violation of the regional hemodynamics of the periodontium ${ }^{6}$. According to the data of Usher AK and Stockley RA, patients with severe chronic periodontitis have an increased risk of developing cardiovascular disease, in part due to the effect of the systemic cytokines and also due to the bacterial products' impact on the vascular endothelial cells, resulting in the development and progression of vascular plaques $^{7}$. Moreover, with unsatisfactory oral hygiene, the associated microorganisms and their genes enter the bloodstream and can be found in atherosclerotic plaques, causing cross-immune reactions ${ }^{8,9}$.

Bronchodilators ( $\beta 2$-agonists of short and long action), anticholinergic drugs, and inhaled corticosteroids (ICS) are used as the main drugs to treat $\mathrm{COPD}^{10}$. However, with the frequent inhalation administration using metered-dose aerosol inhalers or in cases of violating the recommended technique of their use, as a rule, only about $10-20 \%$ of the drug reaches the target, while $80-90 \%$ is deposited in the oral cavity, causing various dysfunctions in the immune defense systems ${ }^{11}$.

Herein is a case history of a 38-year-old patient who was referred for an in-depth dental examination by a cardiopulmonologist due to complaints. The clinical diagnosis included the following: chronic obstructive pulmonary disease, chronic cor pulmonale, stage 2 pulmonary hypertension, hypertension stage II, 3 degrees, and heart failure stage II A with preserved left 
ventricular ejection fraction.

Fluticasone, salmeterol, berodual, amlodipine, cardiomagnil, lisinopril, and atorvastatin had been taken as the basic therapy by the patient for a long time. During the dental examination, the patient complained of a constant dry mouth, distorted taste sensations, a burning tongue, painful teeth sensitivity, and bleeding of the gums when eating. The patient associated all of the complaints with the long-term intake of a large number of medications.

\section{METHODS}

This study was conducted in accordance with the amended Declaration of Helsinki. The Institutional Review Board of Government Institution 'L.T. Malaya Therapy National Institute of the National Academy of Medical Sciences of Ukraine' approved the study, and the participant provided written informed consent.

A dental examination was carried out including the registration of complaints and data from the patient's life and illness history. Unstimulated oral fluid was collected in the morning on an empty stomach in graduated tubes for $10-20$ minutes. To assure data homogeneity, the patient was warned about the prohibition to perform hygienic procedures in the oral cavity, to chew gum, and/or to smoke before the manipulation. The rate of salivation (reference values: $0.3-0.6 \mathrm{ml} / \mathrm{min}$ ), the oral fluid viscosity (norm value: in the range of $1.8-4.1$ relative units), and the $\mathrm{pH}$ value of the mixed saliva (norm value: in the range of 6.8 - 7.2) were calculated. The immunological reactivity of oral tissues was studied by the level of secretory Immunoglobulin A (sIgA) in the mixed saliva using an enzyme immunoassay with a set of reagents ( «Секреторный $\lg \mathrm{A}-И Ф А »$ («XЕMA», Russia).

Cytological and immunocytochemical studies were carried out on the scrapings from the gum epithelium. To assess the cellular composition (neutrophils, monocytes, and lymphocytes), the preparations were stained with hematoxylin-eosin (H\&E), photographed, and selected for analysis in sets of 20 images of cells with clear boundaries. To obtain photographs of the cells, a digital video camera CAM 2800 (lens x40, eyepiece x10) was used. For the histological examination, biopsy material obtained from the area of the gingival papilla was used. The sections $(5-\mu \mathrm{m}$ thick) were stained with $\mathrm{H} \& \mathrm{E}$.

\section{RESULTS}

Upon admission, the general condition of the patient was of moderate severity. Consciousness was clear and their position was active. The skin and visible mucous membranes were clean. There was an expansion of the cervical veins. The peripheral lymph nodes were not enlarged, and there was an increase in anteroposterior chest size (barrel chest). In the lungs, the percussion pulmonary sound was auscultatory with weakened wheezing (dry scattered wheezing; NPV 20 beats per minute). The borders of relative cardiac dullness were right (in IV m/s, according to L. parasternalis dextra), upper (in III $\mathrm{m} / \mathrm{r}$, according to L. parasternalis sinistra), and left (according to L. clavicularis media in $\mathrm{V} \mathrm{m} / \mathrm{r}$ ). There were muffled heart sounds and a splitting of the $2^{\text {nd }}$ heart sound with an emphasis on the pulmonary artery. Additionally, the murmur of the tricuspid valve was insufficient and rhythmic. Blood pressure was measured on the left arm after 5 minutes of rest in a sitting position (110/90 mmHg). Pulse was 94 beats per minute and rhythmic. The abdomen was soft and painless on palpation. Moreover, the liver did not protrude from the edge of the costal arch, Pasternatsky's symptom was absent/negative on both sides, and the feet and legs were pasty.

During the dental examination, the red border of the lips were found to have no pathology. The mucous membrane of the cheeks and lips had dental prints, along with the teeth closing line, and this was edematous. On the cheek, along with the teeth closing line, the mucous membrane was of whitish opacity and tightly adhered to the surface. Palpation of the mucous membrane at the site of the lesion was painless (Figure 1).

The tongue was moderately moist, edematous, and covered with a whitish plaque on the back, which could be easily removed from the surface. At the time of examination, the gum was swollen and congestive hyperemic, while the gingival papillae did not adhere tightly to the teeth surface (Figure 2). Bad breath was detected. Further probing was conducted: bleeding (2.1 per Papillary Bleeding Index (PBI), papillarymarginally-alveolar index (PMA) - 25.0\%, complex periodontal index (CPI) - 3.0 and the periodontal pockets were $4.8 \mathrm{~mm}$ deep. Dental deposits were revealed in large quantities in the form of supragingival and subgingival deposits, and the Green-Vermilion hygiene index was 2.6 (poor oral hygiene).

In areas 14, 13, 12, 11, 21, 22, 23 and 31, 32, 33, 34, 35, $41,42,43,44$ and 45 , there was a limited second degree recession of the gingiva. The $\mathrm{x}$-ray examination results showed the following: destruction of the cortical plate, and the foci of the alveolar bone destruction involved a violation of the alveolar ridge $1 / 3-1 / 2$ of the teeth root length. The diagnosis was chronic generalized periodontitis of moderate severity. 


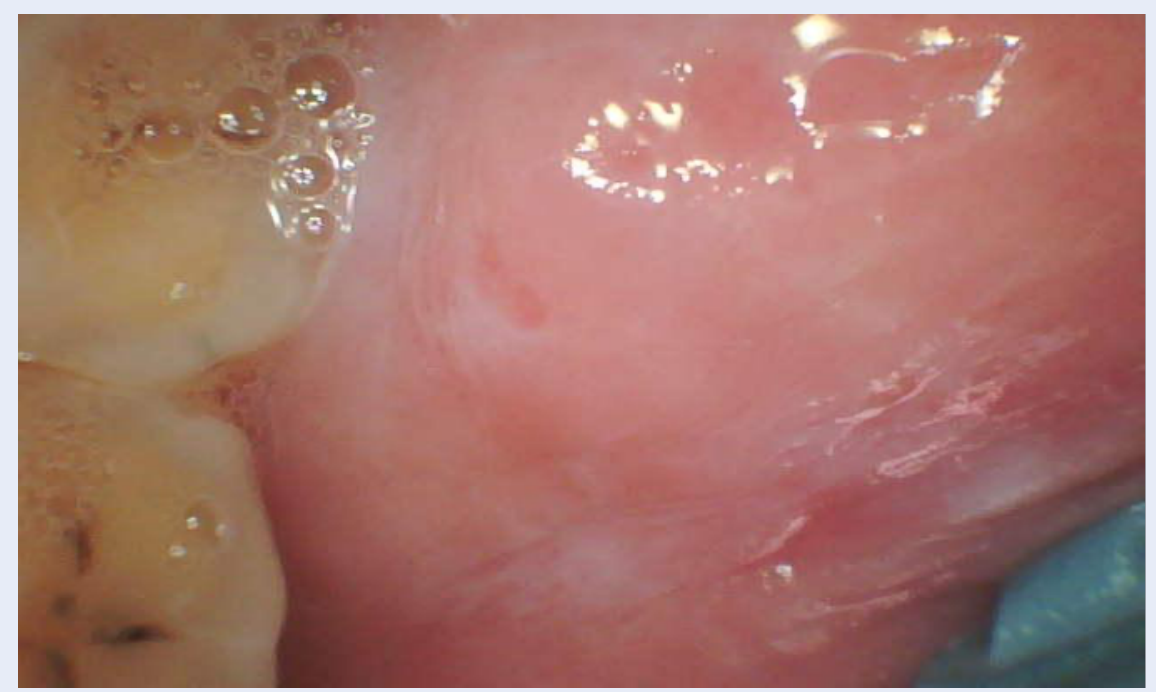

Figure 1: Picture of the oral cavity of the patient with the diagnosis: chronic obstructive pulmonary disease, chronic cor pulmonale, stage 2 pulmonary hypertension, hypertension stage II, 3 degrees. Heart failure stage IIA with preserved left ventricular ejection fraction. Whitish opacity of the cheek mucous membrane in the teeth closing line projection is observed. https://doi.org/10.6084/m9.figshare.16598972.v1

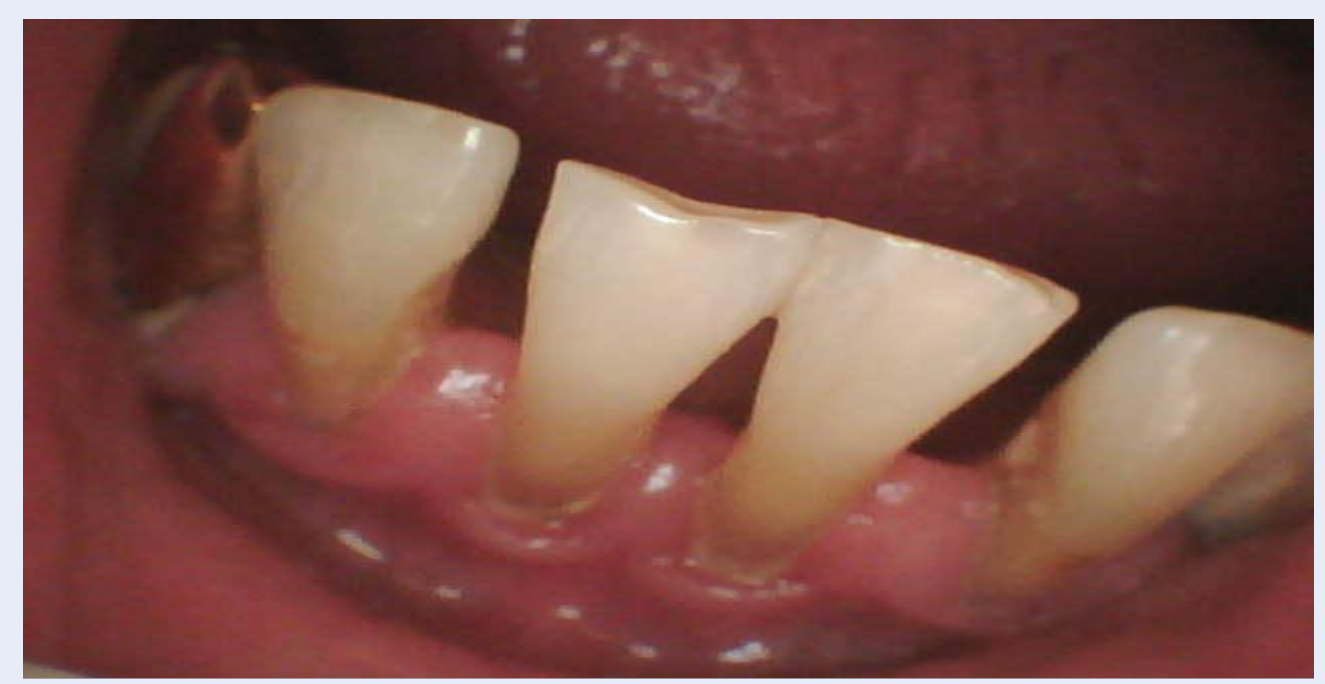

Figure 2: Picture of the gingival margin in the frontal part of the oral cavity of the patient with the diagnosis: chronic obstructive pulmonary disease, chronic cor pulmonale, stage 2 pulmonary hypertension, hypertension stage II, 3 degrees. Heart failure stage II A with preserved left ventricular ejection fraction. https://doi.org/10.608 4/m9.figshare.16598984.v1 


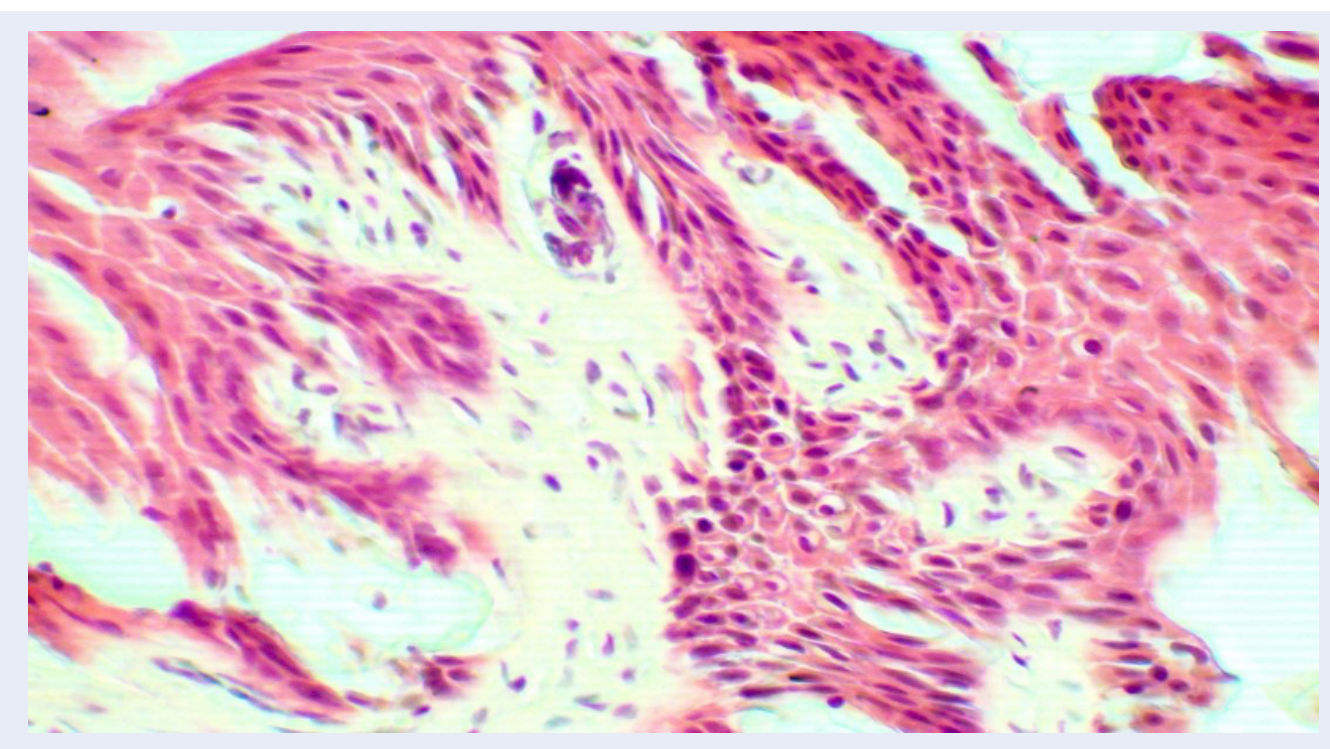

Figure 3: Apical sections of acanthotic bundles with signs of layering violation. Cells of the basal layer with hyperchromic nuclei. Some epithelial cells with the phenomena of hydropic dystrophy. Lack of the clear border between the basal layer of the epithelium and the connective tissue base of gums. Staining with hematoxylin and eosin. (X 400) https://doi.org/10.6084/m9.figshare.16598987.v1

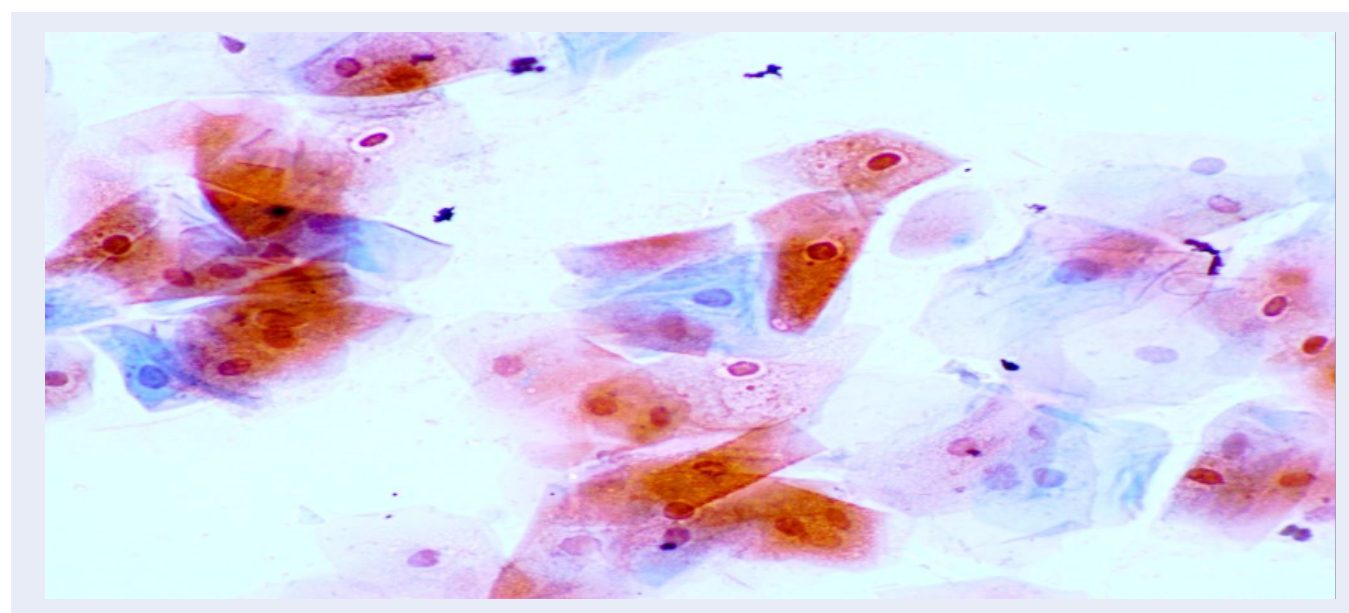

Figure 4: Microphotogram for the cytogram of scraping from the gum surface. Accumulation of cells of the surface and keratinizing layers with the small number of intermediate cells is determined. Papanicolaou smear $\mathrm{x}$ 400. https://doi.org/10.6084/m9.figshare.16599005.v1

The saliva was white, frothy, and viscous, and in insufficient quantity. The salivation rate was $0.26 \mathrm{ml} / \mathrm{min}$, the viscosity was 3.6 relative units, and the $\mathrm{pH}$ was 6.4. The secretory IgA level reached 71.663.During the histological examination of the gums, attention was drawn to the almost widespread thickening of the stratified squamous epithelium and the phenomenon of parakeratosis. The stratification of the layers was violated; the epithelial cells met the phenomena of protein parenchymal dystrophy and the presence of the dysplasia phenomenon was manifested by a violation of the layer stratification, in addition to the increase in the nuclear-cytoplasmic index, hyperchromic nuclei, and the presence of single mitoses (Figure 3).

A detailed cytomorphometric study of the scrapings from the gingival epithelium revealed that the number of parabasal cells was $1 \%$, intermediate $-24 \%$, superficial $-33 \%$, and keratinizing - 42\% (Figure 4 ). The immunocompetent cells were distributed as follows: leukocytes $-22 \%$, neutrophils $-89 \%$, mono- 
cytes $-5 \%$, and lymphocytes $-6 \%$.

\section{DISCUSSION}

The patient's main dental complaint was persistent intense dryness of the mouth. Besides this, the patient complained of distorted taste sensations, a burning tongue, painful sensitivity of the teeth, and bleeding of the gums when eating.

It is known that saliva performs many functions, the main of which is both protective (moisturizing the oral cavity tissues, utilizing food debris and the epithelium, and forming a barrier against antibodies and other active substances), and trophic (maintaining constant hydration and aiding in the physiological regeneration of the mucous membrane). However, the oral fluid performance of these functions depends on its biophysical properties ${ }^{12}$.

Sialometry showed that the reduced salivation rate changed the oral fluid's rheological properties, increased its viscosity, and impaired its cleansing ability. It can be presumed that a significant factor in the development of xerostomia is drug pathomorphosis caused by drug polypharmacy, consisting of the simultaneous use of a large number of drugs with xerogenic properties. For example, $\beta$-2-agonists act on the inhibition of saliva secretion by affecting the $\beta-2$ receptors of the saliva glands ${ }^{13}$. Asthmatic patients treated with $\beta$-2-adrenoceptor agonists have an increased caries susceptibility due to an impaired saliva secretion caused by the use of beta-adrenergic agonists ${ }^{13}$.

On the other hand, $\beta$-blockers and ACE inhibitors contribute to the reduction in renin-angiotensin-aldosterone system (RAAS) activity. They ensure the decrease in pressure in the blood vessels, in addition to vasodilation, and decreasing the volume of regional blood flow, including in the parenchyma of the salivary glands. This can lead to the indicated effects ${ }^{14}$. It was found that the patients under beta-blocker therapy presented with a reduced non-stimulated salivary flow compared to the controls without influencing the sense of taste or masticatory performance ${ }^{14}$.

Our study observed an increase in sIgA levels. This is not consistent with the data of Fukushima et al. (2005), whose study states that inhaled corticosteroids can potentially decrease the total salivary $\operatorname{IgA}^{15}$. However, an increase in this indicator may be the consequence of unsatisfactory oral hygiene and the significant antigenic irritation of the tissues by microorganisms, indicating the activation of the humoral link of pathogenesis. The aim of eliminating foreign agents can normalize impaired homeostasis ${ }^{16,17}$. The reason for the increased sIgA level may be poor oral hygiene and the significant antigenic irritation of tissues by microorganisms. We considered increasing the level of slgA as the compensatory response of the saliva for the restoration of the deficiency of immunoglobulins belonging to other classes. Moreover, we considered the factors of non-specific defense (lysozymes), as well as the direct manifestations of non-specific inflammation that accompany COPD. The patient showed an increase in the number of surface and keratinizing cells of the epithelium, that is, those in the final stages of their differentiation.

A particular feature of healthy oral mucosa is the constant regeneration of epithelium. Epithelial cells are at different stages of their morphofunctional development and gradually move from poorly differentiated to highly specialized cells. As they mature, they shift to the surface layers, undergoing desquamation. This fact is confirmed by the work of Benazir et al. (2020). This showed that the prolonged use of inhalational drugs in patients diagnosed with asthma is associated with changes in the oral epithelial cells ${ }^{18}$. However, in periodontium pathological conditions, a violation occurs in the stages of differentiation, leading to pathological exfoliation. An increase in the desquamation process is observed and this changes the relationship between the different types of epithelial cell. Thus, the functional status of the cells depends on their degree of maturity.

\section{CONCLUSIONS}

Upon summarizing the findings of this clinical case, we postulate that the development and progression of changes in the oral cavity may be associated with both COPD and CHD, especially against the background of long-term medication intake. The nature of the relationship of such lesions is multifaceted. On the one hand, the occurrence, intensity, and course of the changes in the oral cavity depend on the severity of the somatic pathology. On the other hand, the pathology of the oral cavity negatively affects the severity and course of the diseases of the internal organs.

Understanding and studying the possible relationship between lesions in the oral cavity and systemic pathology, especially due to the prolonged or constant use of basic therapy drugs, is of high importance, both on the part of the patient and that of the dentist internist.

\section{CONSENT}

Written informed consent was obtained from the patient for publication of this Case Report and any accompanying images. A copy of the written consent is available for review by the Editor-in-Chief of this journal. 


\section{ABBREVIATIONS}

COPD: chronic obstructive pulmonary disease CHD: coronary heart disease

pH: $\mathrm{pH}$ value

\section{ACKNOWLEDGMENTS}

Not applicable.

\section{AUTHOR'S CONTRIBUTIONS}

N.E. conceived of the study, carried out the clinical studies, drafted the manuscript, Data analysis Guarantor; I.K. Literature search, Clinical studies, participated in the design of the study, Data acquisition, Data analysis. All authors read and approved the final manuscript.

\section{FUNDING}

Not applicable.

\section{AVAILABILITY OF DATA AND MATERIALS}

The basic clinical data used to support the findings of this study are included within the article. The data used to support the findings of this study are restricted in order to protect patient's privacy, but available from the corresponding author upon request. (To contact Dr. N. Emelyanova natadenta@gmail.com).

\section{CONSENT FOR PUBLICATION}

The authors hereby consent that the publisher publishes the work.

\section{CONFLICT OF INTEREST}

There is no conflict of interest.

\section{REFERENCES}

1. Cassol-Spanemberg J, de Rivera-Campillo MER, Otero-Rey EM, Estrugo-Devesa A, Jané-Salas E, López-López J. Oral lichen planus and its relationship with systemic diseases. A review of evidence. J Clin Exp Dent. 2018;10(9):e938-44. PMID: 30386529. Available from: 10.4317/jced.55145.

2. Preshaw PM, Bissett SM. Periodontitis and diabetes. Br Dent J. 2019;227(7):577-84. PMID: 31605062. Available from: 10. 1038/s41415-019-0794-5.

3. Baldomero AK, Siddiqui M, Lo CY, Petersen A, Pragman AA, Connett JE. The relationship between oral health and COPD exacerbations. Int J Chron Obstruct Pulmon Dis. 2019;14:88192. PMID: 31114185 . Available from: 10.2147/COPD.S194991.

4. Shen TC, Chang PY, Lin $\mathrm{CL}$, Chen $\mathrm{CH}$, Tu CY, Hsia TC. Risk of periodontal diseases in patients with chronic obstructive pulmonary disease: a nationwide population-based cohort study. Medicine (Baltimore). 2015;94(46):e2047. PMID: 26579813. Available from: 10.1097/MD.0000000000000874.
5. Carter P, Lagan J, Fortune C, Bhatt DL, Vestbo J, Niven R. Association of Cardiovascular Disease With Respiratory Disease. J Am Coll Cardiol. 2019;73(17):2166-77. PMID: 30846341. Available from: 10.1016/j.jacc.2018.11.063.

6. Carrizales-Sepúlveda EF, Ordaz-Farías A, Vera-Pineda R, FloresRamírez R. Periodontal Disease, Systemic Inflammation and the Risk of Cardiovascular Disease. Heart Lung Circ. 2018;27(11):1327-34. PMID: 29903685. Available from: 10 . 1016/j.hlc.2018.05.102.

7. Usher AK, Stockley RA. The link between chronic periodontitis and COPD: a common role for the neutrophil? BMC Med. 2013;11(1):241. PMID: 24229090. Available from: 10.1186/ 1741-7015-11-241.

8. Cairo F, Gaeta C, Dorigo W, Oggioni MR, Pratesi C, Prato GPP. Periodontal pathogens in atheromatous plaques. A controlled clinical and laboratory trial. J Periodontal Res. 2004;39(6):4426. PMID: 15491349. Available from: 10.1111/j.1600-0765.2004 00761.x.

9. Atarbashi-Moghadam F, Havaei SR, Havaei SA, Hosseini NS, Behdadmehr G, Atarbashi-Moghadam S. Periopathogens in atherosclerotic plaques of patients with both cardiovascular disease and chronic periodontitis. ARYA Atheroscler. 2018;14(2):53-7. PMID: 30108636. Available from: 10.22122/ arya.v14i2.1504.

10. Global Initiative for Chronic Obstructive Lung Disease (GOLD). Global strategy for the diagnosis, management, and prevention of chronic obstructive pulmonary disease. 2019;Available from: www.goldcopd.com.

11. Chen $S$, Small M, Lindner $L, X u X$. Symptomatic burden of COPD for patients receiving dual or triple therapy. Int J Chron Obstruct Pulmon Dis. 2018;13:1365-76. PMID: 29731624. Available from: 10.2147/COPD.S163717.

12. Liena-Puy $C$. The rôle of saliva in maintaining oral health and as an aid to diagnosis. Med Oral Patol Oral Cir Bucal. 2006;11(5):E449-55. PMID: 16878065.

13. Ryberg M, Möller C, Ericson T. Saliva composition and caries development in asthmatic patients treated with beta 2-adrenoceptor agonists: a 4-year follow-up study. Scand J Dent Res. 1991;99(3):212-8. PMID: 1871531. Available from: 10.1111/j.1600-0722.1991.tb01887.x.

14. de Matos LF, Pereira SM, Kaminagakura E, Marques LS, Pereira CV, van der Bilt A. Relationships of beta-blockers and anxiolytics intake and salivary secretion, masticatory performance and taste perception. Arch Oral Biol. 2010;55(2):164-9. PMID: 20018274. Available from: 10.1016/j.archoralbio.2009.11.011.

15. Fukushima C, Matsuse H, Saeki S, Kawano T, Machida I, Kondo $\mathrm{Y}$. Salivary $\lg \mathrm{A}$ and oral candidiasis in asthmatic patients treated with inhaled corticosteroid. J Asthma. 2005;42(7):601-4. PMID: 16169797. Available from: 10.1080/ 02770900500216259.

16. Bozejac BV, Stojšin I, M, Zvezdin B, Brkanić T, Budišin E. Impact of inhalation therapy on the incidence of carious lesions in patients with asthma and COPD. J Appl Oral Sci. 2017;25(5):50614. PMID: 29069148. Available from: 10.1590/1678-77572016-0147.

17. Takeuchi K, Matsumoto K, Furuta M, Fukuyama S, Takeshita T, Ogata H. Periodontitis Is Associated with Chronic Obstructive Pulmonary Disease. J Dent Res. 2019;98(5):534-40. PMID: 30848974. Available from: 10.1177/0022034519833630.

18. Benazir MI, Prasad H, Rajmohan M, Srichinthu KK, Prema P, Mahalakshmi L. Effect of Inhalational Therapy on Buccal Mucosal Cells in Asthmatic Patients: A Cytological Study. Rambam Maimonides Med J. 2020;11(4):e0031. PMID: 32441649. Available from: 10.5041/RMMJ.10405. 
Ready to submit your manuscript? Choose Biomedpress and benefit from:

- Fast, convenient online submission

- Through peer-review by experienced researchers

- Rapid publication on acceptance

- Free of charge (without publication fees)

Learn more http://www.biomedpress.org/journals/

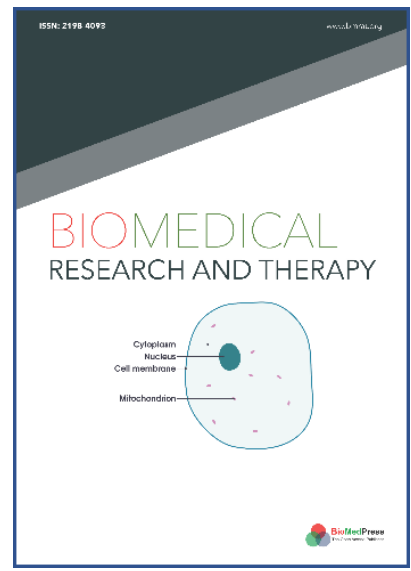

\title{
Biomedical Research and Therapy
}

Indexed: Web of Science (ESCl), Embase, Google Scholar

Journal Citation Indicator (2020): 0.16

Acceptance Rate (2020): 54.32\%

Article Publishing Charge: Free

Submission to first editorial decision: 27 days

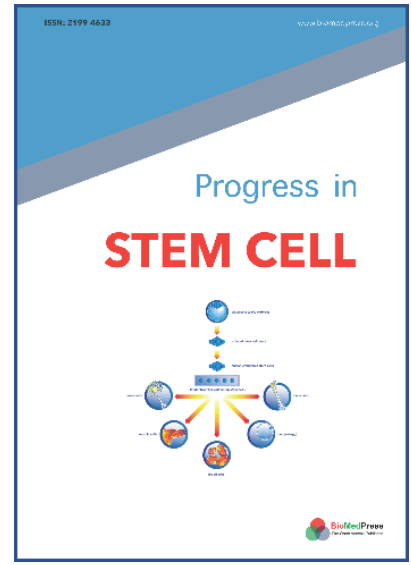

\section{Progress in Stem Cell}

Indexed: Embase, Google Scholar

Acceptance Rate (2020): 78.19\%

Article Publishing Charge: Free

Submission to first editorial decision: 19 days

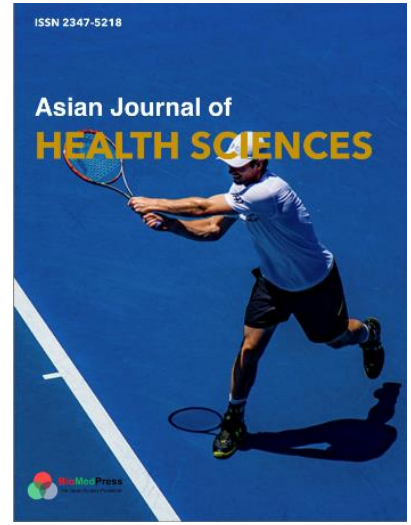

\author{
Asian Journal of Health Sciences \\ Indexed: Google Scholar \\ Acceptance Rate (2020): 72.89\% \\ Article Publishing Charge: Free \\ Submission to first editorial decision: 16.5 days
}

